\title{
ОБЩАЯ ХАРАКТЕРИСТИКА ФИТОПАТОГЕННЫХ ГРИБОВ, ВСТРЕЧАЮЩИХСЯ НА НЕКОТОРЫХ КОРМОВЫХ РАСТЕНИЯХ АЗЕРБАЙДЖАНА
}

\section{GENERAL CHARACTERISTICS OF PHYTOPATHOGENIC FUNGI MEETING ON SOME FODDER PLANTS OF AZERBAIJAN}

\section{A. Yusifova}

Summary. In the carried out of researcher studied the species composition of mycobiota and the specific gravity of phytopathogens of a number of fodder plants in some regions of Azerbaijan. It was found that on the fodder plants selected for research was spreaded 87 species of micromycetes most of which (72.4\%) belongs to the anamorphs of sac fungi. About half of all mycobiota of registered fungi are phytopathogens, that cause fusarium, wilting, rust, spotting, rot, and other plant diseases. The presence of dominant and frequently encountered species among these fungi in the studied areas shows the importance of ensuring the mycological safety of fodder plants.

Keywords: fodder plants, mycobiota, anamorphic fungi, phytopathogens, frequency of occurrence, dominants.
$\mathbf{H}$ еуклонный рост мирового населения начиная со второй половины двадцатого века стал вызывать ряд недостатков, проявляемых в энергоресурсах, пищевых продуктах, а также в сырье для различных отраслей промышленности [16]. К сожалению, масштабы проблемы увеличиваются, и в той или иной степени она начинает ощущаться во всем мире. По этой причине решение этих проблем естественным образом конкретизирует задачи современной науки, особенно биологии, которые в настоящее время охватывают два направления (создание новых источников и повышение эффективности существующих источников).

На фоне задач, поставленных исследованиями, проводимыми в этом направлении, обеспечение мирового населения сельскохозяйственной продукцией, в том числе продукцией животноводства, находится в центре внимания. Так, продукты животного происхождения являются одним из основных и традиционных источников питания человека и будут сохранять свою важность еще долгое время.
Юсифова Анаханум Амралы кызы

Доктор философии по аграрным наукам, доцент, Азербайджанский Государственный Педагогический Университет azmbi@mail.ru

Аннотация. В проведенных исследованиях изучен видовой состав микобиоты и удельный вес фитопатогенов ряда кормовых растений некоторых регионов Азербайджана (Аранский, Ленкоранский и Апшеронский экономические районы). Установлено, что в отобранных для исследования кормовых растениях распространено 87 видов микромицетов, большая часть которых (72,4\%) относится к анаморфам сумчатых грибов. В числе зарегистрированных грибов около половины всей микобиоты составляют фитопатогены, вызывающие фузариоз, увядание, ржавчину, пятнистость, гниль и др. заболевания растений. Присутствие среди них видов, являющихся для исследуемых территорий доминирующими или часто встречающимися, показал важность учета микологической безопасности кормовых культур.

Ключевые слова: кормовые растения, микобиота, анаморфные грибы, фитопатогены, частота встречаемости, доминанты.

Кормовые культуры также играют важную роль в производстве продуктов животноводства $[15,18]$, поскольку продуктивность животных, выращиваемых для получения пищевых продуктов, а также качественный состав продуктов в значительной степени зависят от употребляемого ими корма.

Растения составляют основную часть кормового рациона крупного и мелкого рогатого скота, выращиваемого для пищевых целей. Растения являются источниками питания не только для животных, но и для микроорганизмов, в том числе грибов. Результатом этого являются сформировавшиеся различные взаимоотношения между растениями и грибами, одной из которых является патология, вызываемая грибами у растений [10]. Так, ежегодные потери урожая из-за грибковых заболеваний измеряются миллионами тонн [2]. Ущерб, наносимый грибами растениям, этим не ограничивается, и грибы также обогащают растения, на которых они обитают, метаболитами, производимыми ими в результате своей жизнедеятельности, 
а среди них присутствуют и такие, которые могут вызвать опасные последствия как для самих животных, так и для организмов, использующих их в пищевых целях. Микотоксины, которые по действию сравнивают с оружием массового уничтожения и синтезируются грибами [19], являются ярким примером этого. Чтобы предотвратить заболевания, вызываемые грибами, очень важно всестороннее изучение растений, используемых животными в качестве корма, и пополнение базы данных для разработки эффективных мер борьбы с этими грибами.

Важная роль в экономике Азербайджанской Республики принадлежит аграрному сектору, дикорастущие и выращиваемые кормовые культуры на ее территории [1], позволяют отметить то, что поставленные вопросы не чужды нашей стране. Поэтому целью данной работы было изучение видового состава микобиоты ряда кормовых растений, произрастающих и возделываемых в отдельных районах Азербайджана, и определение удельного веса фитопатогенных видов, участвующих в формировании их микобиоты.

\section{Материалы и метолы}

Объектами исследования явились дикорастущие и культивируемые кормовые культуры (Agrostis alba L., Artemisia vulgaris L., Beta vulqaris L., Cynodon dactylon (L.) Pers., Hordeum vulgare L., Lotus L., Malva neglecta Wailler, Medicago sativa L., Phleum pratense L., Trifolium pratense L., T.repens L., Triticum aestivum L., T.durum Desf, Vicia sativa L., V.villosa Roth. və Zea mays L.) и населяюшие их грибы территорий Аранского, Лянкяранского и Апшеронского экономических районов Азербайджана. Отбор проб продолжался с апреля по ноябрь, и пробы были взяты из вегетативных и генеративных органов растений, предположительно заселенных грибами. В целом за время исследования было взято около 500 проб и проанализировано в соответствии с целью работы. В ходе исследования отбор образцов, выделение обнаруженных на них грибов в чистую культуру, хранение рабочих культур проводились по известным микологическим методам [5-6].

Для выделения грибов в чистую культуру были использованы такие питательные среды, как агар Сабуро, сусло-агар, агар Чапека, картофельный и рисовый агар.

Идентификация грибов проводилась на основе известных определителей [3, 7-9, 11-12, 17], составленных на основе их культурально-морфологических и физиологических характеристик.

Частоту встречаемости грибов (\%) определяли по формуле $\mathrm{P}=(\mathrm{n} / \mathrm{N}) \mathrm{x} 100$, где $\mathrm{P}$ - частота встречае- мости, $\mathrm{n}$ - количество образцов с грибами, $\mathrm{N}$ - общее количество взятых образцов.

\section{Результаты и их обсужАение}

Исследования, проведенные в 2015-2019 годах, показали, что на 16 видах дикорастущих и культурных растений 3-х экономических районов Азербайджана (Абшеронский, Аранский и Ленкоранский) распространены 87 видов настоящих грибов (Mycota). Большинство зарегистрированных грибов, то есть 63 вида, относятся к анаморфам сумчатых грибов - Ascomycota (Alternaria alternata, A.tenuissima, Alternaria solani, A.tenuis, Asc. betae, Asc.hordei, Asc.pisi, Asc.sojikota, Aspergillus candidus, A.flavus, A.fumigatus, A.nidulans, A.niger, A.ochraceus, A.ustus, A.versicolor, Blumeria graminis, Botrytis cinerea, Cehpalosporium lecanii, Cercospora beticola, C.fabae, Cladosporium cladosporioides, C.herbarium, Cochliobolus heterostrophus, Colletotrichum trifolii, Colletotrichum gloesporioides, Fusarium avenaceum, F.culmorum, F.gibbosum, F.moniliforme, F.oxysporium, F.solani, F.semitectum, F.sporotrichioides, Paecilomyces variotii, Penicillium brevicompactum, P. chrysogenum, P.expansum, P. glabrum, P.martensii, P.notatum, P. purpurogenum, P. thomii, Phoma betae, Ph.destructiva, Ph.medicaginis, Phomopsis leptostromiforme, Pyrenophora graminea, Septoria nodorum, Septoria pisi, S.sojina, S.tritici, Stemphilium botryosum, Thielaviopsis basicola, Trichoderma atroviride, T.asperellum, T.harzianum, T.polysporum, T.viride, Trichothecim roseum, Verticillium bulbillosum, V.dahliae, V.nigrescens,), 8 видов (Absidia ramosa, Mucor circinelloides, M.globosum M. hiemalis, M.mucedo, M.racemosus, Rhisopus nigricans, Rh. Stolonifer) к зигомицетам (Zygomycota), 9 видов (Claviceps purpurea, Eryshiphe betae, E.communis, E.pisi, Gibberella fujikuroi, Monilia cytophila, Pyrenophora graminea, Sclerotina libertiana и S.Sclerotiorum)- к телеоморфам сумчатых грибов, 7 видов (Puccinia recondita, Rhizoctonia solani, Tilletia caries, Urocystis cepulae, Uromyces trifolii-repentis, Ustilago hordei и U.zeae) относятся к базидиомицетам (Bazidiomycota).

Численное превосходство видов сумчатых грибов в кормовых растениях, является одной из характерных черт микобиоты природы Азербайджана. Так, в большинстве исследований к настоящему времени неоднократно подтверждалось преобладание анаморф сумчатых грибов в формировании микобиоты у растений, в первую очередь, принадлежащих по своей жизненной форме к травам [4].

Как уже отмечалось, между грибами и растениями сложились различные взаимоотношения, одно из которых проявляется в том, что грибы вызывают у растений различные патологии. Среди грибов, обнару- 
Таблица 1. Оценка общей и фитопатогенной микобиоты исследованных кормовых растений

\begin{tabular}{|c|c|c|c|c|}
\hline № & Название растений & $\begin{array}{l}\text { Количество грибов участвующих } \\
\text { в формировании общей микобиоты } \\
\text { (шт.) }\end{array}$ & $\begin{array}{l}\text { Количество } \\
\text { фитопатогенов (шт.) }\end{array}$ & $\begin{array}{l}\text { Удельный вес } \\
\text { фитопатогенов(\%) }\end{array}$ \\
\hline 1 & Agrostis alba & 11 & 4 & 36,4 \\
\hline 2 & Artemisia vulgaris & 9 & 3 & 33,3 \\
\hline 3 & Beta vulqaris & 17 & 10 & 58,8 \\
\hline 4 & Cynodon dactylon & 12 & 6 & 50,0 \\
\hline 5 & Hordeum vulgare & 18 & 10 & 55,6 \\
\hline 6 & Lotus L. & 11 & 5 & 45,5 \\
\hline 7 & Malva neglecta & 15 & 7 & 46,7 \\
\hline 8 & Medicago sativa & 23 & 15 & 65,2 \\
\hline 9 & Phleum pratense & 15 & 7 & 46,7 \\
\hline 10 & Trifolium pratense & 20 & 11 & 55,0 \\
\hline 11 & T.repens & 18 & 9 & 50,0 \\
\hline 12 & Triticum aestivum & 16 & 7 & 43,8 \\
\hline 13 & T.durum & 15 & 7 & 46,7 \\
\hline 14 & Vicia sativa & 13 & 5 & 38,5 \\
\hline 15 & V.villosa & 12 & 6 & 50,0 \\
\hline 16 & Zea mays & 18 & 10 & 55,6 \\
\hline
\end{tabular}

женных на кормовых растениях в ходе исследований, есть виды, о вызываемых патологиях которых имеется достаточная информация. Примерами могут служить виды грибов родов Alternaria, Ascochyta, Botrytis, Fuzarium, Phoma, Puccina, Septoria, Urocystis, Uromyces, Verticillium и др. Так, виды грибов, вызывающие у различных растений такие заболевания, как фузариоз, увядание, пятнистость (разной формы и цвета), гниль разной окраски, ржавчина, мучнистая роса и т.д. и приводящие к серьезным изменениям как морфологических, так и физиолого-биохимических параметров относятся именно к отмеченным выше родам. Так, например, такие грибы как В. cinerea, вызывающий серую гниль, V. dahliae, вызывающий увядание, F. moniliforme и F. oxysporum, вызывающие фузариоз, E. communis, вызывающий мучнистую росу, A. alternata, вызывающий альтернариоз и др. являются характерными видами этих родов, и в ходе исследований было установлено, что они распространены во взятых образцах кормовых растений Азербайджана. Кроме того, многие из них, такие как Fusarium oxysporium и Verticillium dahile, вызывают заболевания у сотни видов растений, т.е. они являются универсальными патогенами, не обладающими субстратной специфичностью. Наряду с этим, многие из этих грибов обладают способностью синтезировать ряд биологически активных веществ в результате жизнедеятельности, некоторые из которых полезны с точки зрения практических нужд, а другие вызывают развитие серьезных негативных последствий для здоровья человека.
По этой причине частота их встречаемости используется для выяснения характера функций, выполняемых грибами в той или иной экосистеме, а также для определения удельного веса грибов в формировании гетеротрофного блока экосистемы. Это также важно с точки зрения обеспечения микологической безопасности произрастающих или культивируемых в конкретной экосистеме растений пищевого, кормового и медицинского назначения. С учетом этого было целесообразным охарактеризовать зарегистрированные грибы как по распространению на отдельных растениях, так и по частоте встречаемости отдельных видов грибов в общих отобранных пробах.

При определении распределения на отдельных растениях зарегистрированных, а также получивших подтверждение фитопатогенности грибов выявлено, что растение Medicago sativa характеризуется самым высокими, а Artemisia vulgaris - самыми низкими показателями как общей микобиоты, так количества фитопатогенов (Таблица 1). Так, более половины из 23 видов грибов, участвующих в формировании микобиоты Medicago sativa, а точнее $65,2 \%$, относятся к фитопатогенам, включающие такие виды как A. alternata, Botrytis cinerea, Erysiphe pisi, F. moniliforme, F. oxysporium, Phoma medicaginis, Thielaviopsis basicola, Uromyces trifoliirepentis, Verticillium dahliae и др. Многие из этих видов также встречаются в таких растениях, как Trifolium pratense и T. repens, что связано с их таксономической близостью. 
Таблица 2. Характеристика частоты встречакмости грибов, встречающихся на отобранных образцах кормовых растений

\begin{tabular}{|c|c|c|c|}
\hline Оцениваемые параметры & Доминанты & Часто встречающиеся & Случайные и редкие виды \\
\hline $\begin{array}{l}\text { Количественный показатель } \\
\text { частоты встречаемости }\end{array}$ & $40,5-52,7 \%$ & $11,2-36,8 \%$ & $0,008-7,9 \%$ \\
\hline $\begin{array}{l}\text { Общее количество } \\
\text { соответствующих грибов }\end{array}$ & 6 & 38 & 43 \\
\hline Количество фитопатогенов & 3 & 21 & 28 \\
\hline $\begin{array}{l}\text { Названия соответствующих } \\
\text { фитопатогенов }\end{array}$ & $\begin{array}{l}\text { A.alternata, } \\
\text { F.oxysporium } \\
\text { V.dahile }\end{array}$ & $\begin{array}{l}\text { Alternaria solani, A.tenuis, } \\
\text { Asc.betae, Asc.hordei, Asc.pisi, } \\
\text { Botrytis cinerea, Cercospora } \\
\text { fabae, Colletotrichum trifolii, } \\
\text { F.avenaceum, F. gibbosum, } \\
\text { F.moniliforme, F.solani, } \\
\text { F.semitectum, Phoma betae, } \\
\text { Ph.destructiva, Ph.medicaginis, } \\
\text { Septoria pisi, Stemphilium } \\
\text { botryosum } \\
\text { Thielaviopsis basicola, Ustilago } \\
\text { zeae }\end{array}$ & $\begin{array}{l}\text { Alternaria tenuissima, } \\
\text { Asc.sojikota, Blumeria graminis, Cercospora } \\
\text { beticola, } \\
\text { Claviceps purpurea, } \\
\text { Cochliobolus heterostrophus, Colletotrichum } \\
\text { gloesporioides, } \\
\text { Eryshiphe betae, E.communis, E.pisi, Fusarium } \\
\text { culmorum, F.sporotrichioides, } \\
\text { Gibberella fujikuroi, } \\
\text { Monilia sitophila, Pyrenophora graminea, } \\
\text { Phomopsis leptostromiforme, } \\
\text { Puccinia recondita, Rhizoctonia solani, } \\
\text { Sclerotina libertiana, S.sclerotiorum, Septoria } \\
\text { nodorum, S.sojina, S.tritici, Tilletia caries } \\
\text { Trichothecim roseum, Urocystis cepulae, } \\
\text { Uromyces trifolii-repentis, Ustilago hordei }\end{array}$ \\
\hline
\end{tabular}

Что касается частоты встречаемости фитопатогенных видов грибов в общих образцах, взятых в ходе исследования, то из полученные результаты показали, что во всех исследуемых зонах 6 видов характеризуются частотой встречаемости, свойственной доминирующим видам (таблица 2). Как видно, из грибов с частотой встречаемости более

40\% 3 вида, т.е. A. alternata, F. oxysporium и V. dahile, относятся к фитопатогенам, то есть 50\% доминант относятся к фитопатогенам.

Из зарегистрированных видов грибов 38 характеризуются частотой встречаемости, характерной для часто встречающихся грибов, а ее количественное значение колеблется в пределах 11,2-36,8\%. 55,3\% грибов, соответствующих этой характеристике, относятся к фитопатогенам.

Случайные и редкие виды по сравнению с другими, характеризуются более высокими показателями, как по количеству видов, так и по удельному весу фитопатогенов $(65,1 \%)$.

Следует отметить, что исследуемые экономические районы отличаются естественными почвенно-климатическими условиями [1], и это различие приводит к формированию для каждой зоны специфической микобиоты, которая проявляется как в видовом составе, так и в частоте встречаемости отдельных фитопатогенов.
Так, из 87 видов, зарегистрированных в ходе исследований, 75 видов участвуют в формировании микобиоты кормовых растений Ленкоранского, 70 видов - Аранского и 62 - Апшеронского экономических районов. Кроме того, 25 видов, зарегистрированных на территории Ленкоранского экономического района, не обнаружено на Апшеронском полуострове и 12 видов, зарегистрированных на территории Апшеронского полуострова - в Ленкоранском экономическом районе. Согласно аналогичному подходу, из грибов, обнаруженных на территории Аранского экономического района, 12 видов не выявлено в Ленкорани и 6 видов - на Апшероне. При обратном сравнении Апшерона и Арана таких видов было 8. Все это позволяет отметить, что естественные почвенно-климатические условия Ленкоранского экономического района более благоприятны для распространения грибов.

В то же время следует подчеркнуть, что эпифитотия того или иного заболевания на исследуемых территориях до сих пор не обнаружена, что позволяет констатировать, что фитосанитарное состояние исследуемых территорий не опасное, но наблюдаемое возрастание некоторых заболеваний (фузариоз, увядание и мучнистая роса) указывает на важность удержания в центре внимания этого вопроса и принятия профилактических мер по улучшению фитосанитарной ситуации.

Таким образом, в результате исследований выявлено, что в формировании микобиоты кормовых растений 
в Апшеронском, Аранском и Ленкоранском экономических районах Азербайджана участвуют 87 видов настоящих грибов, в числе которых есть фитопатогены, вызывающие опасные заболевания растений. Изучаемые растения различаются между собой как по участвующим в форми- ровании общей микобиоты грибам, так и по распределению фитопатогенных грибов по субстратам, а также в целом по частоте встречаемости грибов на отобранных образцах. Все эти данные могут быть полезны при разработке профилактических мер против фитопатогенов.

\section{ЛИТЕРАТУРА}

1. Азербайджанская Национальная Энциклопедия. В 25 томах. Азербайджанский том. Баку: Научный центр «Азербайджанская Национальная Энциклопедия», 2007, 884c.

2. Атлас экономически значимых растений и вредных объектов России и сопредельных государств.// http://www.agroatlas.ru/diseases

3. Болезни культурных растений./ Под общей редакцией В. А. Павлюшина. СПб, 2005. - 288 c.

4. Гаджиева Н.Ш., Мамедов Г. М., Эюбов Б. Б., Мамедова Ф. Р., Гахраманова Ф. Х., Джабраилзаде С. М. Патогенные грибы, обитающие на растениях, культурно возделываемых в условиях Азербайджана.// Вестник МГОУ, серия «Естественные науки», 2012, № 5, с. 9-12

5. Методы экспериментальной микологии/Под. ред. Билай В. И. Киев: Наукова думка, 1982, 500с.

6. Нетрусов А.И., Егорова М. А., Захарчук Л. М. и др. Практикум по микробиологии.- М.: Издательский центр «Академия», 2005, 608с.

7. Саттон Д., Фотергилл А., Риналди М. Определитель патогенных и условно патогенных грибов. М.: Мир, 2001, 486с.

8. Семенкова И.Г., Соколова Э.С. Фитопатология. М.: Академия, 2003, 479с.

9. Хохряков М.К., Доброзракова Т. Л., Степанов К. М., Летова М. Ф. Определитель болезней растений. СПб: Лань, 2003, 592 с

10. Archana J., Surendra S., Qin W., Yuanfu L. \& Jingshan Sh. A review of plant leaf fungal diseases and its environment speciation.// Bioengineered, 2019, 10:1, 409-424

11. Ellis M.B., Ellis J. P. Microfungi on Land plants. An identification Handbook. London: Helm, 1987, 819p.

12. Kirk P.M., Cannon P. F., David J.C., Stalpes J. A. Ainsworth and Bisby's Dictionary of the fungi(9 ed.) Oxon, Wallingford: CAB International, 2001, 655 p.

13. Knapp S., Van der Heijden M.G.A. A global meta-analysis of yield stability in organic and conservation agriculture.// Nat Commun, 2018, 9, 3632. https://doi. org/10.1038/s41467-018-05956-1

14. Lawrence P.R., Meghan C. W-R., Debra K. A., Teresa A. D. Importance of Animals in Agricultural Sustainability and Food Security.// The Journal of Nutrition, 2015, v. 145 , is. 7, p.1377-1379.

15. Ma Y., Luo B., Zhu Q. et al. Changes in traditional ecological knowledge of forage plants in immigrant villages of Ningxia, China.// J Ethnobiology Ethnomedicine, 2019, 15, 65. https://doi.org/10.1186/s13002-019-0333-0

16. Owusu P.A., \& Asumadu-Sarkodie S. A review of renewable energy sources, sustainability issues and climate change mitigation. //Cogent Engineering, 2016, 3(1), 1167990. https://doi.org/10.1080/23311916.2016.1167990

17. Samson R.A., Pitt J. I. Integration of modern taxonomic methods for Penicillium and Aspergillus classification. Amsterdam: Harwood Publishers, 2000, 510p.

18. Thornton Ph. K. Livestock production: recent trends, future prospects.// Philos Trans R Soc Lond B Biol Sci., 2010, v.27, i.365(1554): p.2853-2867.

19. Zain ME. Impact of mycotoxins on humans and animals. J Saudi Chem Soc. 2011;15:129-144. 